\title{
RANCANG BANGUN SISTEM INFORMASI PARIWISATA DAN BUDAYA BERBASIS WEB MENGGUNAKAN GOOGLE API PADA KANTOR PARIWISATA DAN KEBUDAYAAN KABUPATEN BLORA
}

\author{
Danang Danang \\ Program Studi Teknik Elektro \\ Sekolah Tinggi Elektronika dan Komputer Semarang \\ Email: danang@stekom.ac.id \\ Febryantahanuji Febryantahanuji \\ Program Studi Manajemen Informatika \\ Sekolah Tinggi Elektronika dan Komputer Semarang \\ Email: febryantahanuji@stekom.ac.id \\ Rima Febriana Maryati \\ Program Studi Sistem Komputer \\ Sekolah Tinggi Elektronika dan Komputer Semarang \\ Email: rimafebriana.maryati@stekom.ac.id
}

\begin{abstract}
ABSTRAK
Perkembangan teknologi komputer yang semakin pesat media internet merupakan salah satu penyampaian informasi yang sangat efektif. Melalui internet berbagai macam informasi dari berbagai macam bidang didapatkan secara cepat. Internetpun menjadi bagian penting sebagai wadah atau media promosi. Dengan faktor kelebihan internet tersebut, peneliti mencoba untuk memberikan informasi tentang keberadaaan pariwisata dan budaya yang ada di Blora agar diketahui oleh masyarakat kota Blora pada khususnya dan masyarakat luar kota Blora pada umumnya dengan mudah dan hemat waktu. Kabupaten Blora merupakan kabupaten yang mempunyai potensi wisata yang meliputi wisata belanja, wisata alam, wisata budaya maupun kuliner. Wisata belanja di Blora sangat beragam bagi para wisatawan yang akan berbelanja produk kerajinan dan sebagainya. Wisata budaya yang ditawarkan berupa tradisi dan adat istiadat serta keunikan khas yang ada di Blora. Sedangkan wisata kuliner yang terdapat di Blora berupa makanan khas dan jajanan khas Blora. Perancangan sistem ini dibuat melalui beberapa tahap, yaitu dari mulai menganalisa permasalahan, desain sistem, dan sampai ke tahap pengujian. Software pendukung yang digunakan adalah Apache, Macromedia Dreamweaver MX dan PHP sebagai server sidescripting dan output yang dihasilkan berupa sebuah website yang menyediakan informasi dan dapat tercapai peningkatan yang optimal dalam bidang pariwisata dan budaya di Kabupaten Blora yang dapat lebih mengangkat citra Kabupaten Blora sebagai kota wisata dan budaya.
\end{abstract}

Kata kunci: teknologi, informasi, pariwisata, budaya, blora.

\begin{abstract}
With the rapid development of computer technology the internet media is one of the most effective information delivery. Through the internet various kinds of information from various fields are obtained quickly. Internetpun become an important part as container or media campaign. With the advantages of the Internet, researchers try to provide information about the existence of tourism and culture in Blora to be known by the people of Blora city in particular and people outside the city of Blora in general with easy and time saving. Blora Regency is a district that has tourism potential that includes shopping, nature tourism, cultural and culinary tourism. Shopping in Blora is very diverse for tourists who will shop for handicraft products and so forth. Cultural tourism offered in the form of traditions and customs and unique uniqueness that exist in Blora. While the culinary tours contained in Blora in the form of typical food and typical snacks Blora.The design of this system is made through several stages, namely from start to analyze the problems, system design, and up to the testing phase. The supporting software used is Apache, Macromedia Dreamweaver MX and PHP as a side-scripting server and the end result of this research is a website that provides information and can be achieved optimum improvement in tourism and culture in Blora Regency that can further lift the image of Blora Regency as a tourist and cultural city.
\end{abstract}

Keywords: technology, information, tourism, culture, blora. 


\section{PENDAHULUAN}

Kemajuan ilmu pengetahuan dan teknologi semakin berkembang pesat, khususnya pada bidang komputerisasi yang perkembangannya juga menembus ke segala aspek kehidupan dalam masyarakat. Sistem informasi dengan menggunakan komputer sangat penting dalam mendukung perkembangan masyarakat dunia yang sedang menuju ke arah informasi, seiring dengan kebutuhan akan informasi yang cepat dan akurat sehingga diperlukan sebuah cara agar informasi dapat diakses oleh semua orang dimanapun mereka berada.

Seiring berjalannya waktu, banyak yang sudah menggunakan media internet sebagai media promosi yang murah dan cepat. Promosi online pun memiliki kelebihan yaitu tidak terbatas ruang dan waktu, kapanpun dan dimanapun orang bisa mengakses website. Berbeda dengan promosi offline yang memerlukan biaya mahal dan terbatas oleh ruang dan waktu, serta terbatas oleh wilayah tertentu.

Kabupaten Blora merupakan kabupaten yang mempunyai potensi wisata yang meliputi wisata belanja, wisata alam, wisata budaya maupun kuliner. Wisata belanja di Blora sangat beragam bagi para wisatawan yang akan berbelanja produk kerajinan dan sebagainya. Wisata budaya yang ditawarkan berupa tradisi dan adat istiadat serta keunikan khas yang ada di Blora [6], sedangkan wisata kuliner yang terdapat di Blora berupa makanan khas dan jajanan khas Blora.

Perkembangan teknologi komputer, timbul berbagai macam permasalahan yang berkaitan dalam bidang pariwisata dan budaya Kota Blora, antara lain kurangnya pembinaan terhadap wisata dan budaya daerah yang berakibat kurangnya minat mayarakat untuk mengembangkan dan melestarikan wisata dan budaya daerah, yang berakibat menurunnya keadaan wisata dan budaya daerah di Kabupaten Blora, belum optimalnya pemberdayaan masyarakat pariwisata yang menyebabkan kurangnya kesadaran masyarakat untuk mengembangkan pariwisata dan budayanya, serta belum tersedianya fasilitas informasi dan pemasaran pariwisata. Hal ini menyebabkan banyak wisatawan yang sengaja datang jauh-jauh ke Kabupaten Blora untuk berwisata tidak mendapatkan informasi yang cukup mengenai potensi, ragam budaya dan pariwisata yang terdapat di Kabupaten Blora sehingga potensi wisata dan budaya di Kabupaten Blora terasa sepi, belum dikenal oleh banyak orang dan tidak berkembang.

Dari beberapa hal diatas, maka diperlukan fasilitas publik yang dapat mengakomodasi kegiatan penyampaian informasi mengenai pariwisata dan budaya di Kabupaten Blora. Sekaligus dijadikan sebagai tempat promosi pariwisata Kabupaten Blora serta sebagai tempat pengembangan budaya Kabupaten Blora. Diharapkan dapat tercapai peningkatan yang optimal dalam bidang pariwisata dan budaya di Kabupaten Blora yang dapat lebih mengangkat citra Kabupaten Blora sebagai kota wisata dan budaya, Sedangkan sebagai perbandingan peneliti mengambil jurnal dengan judul "Perancangan dan Pembangunan informasi geografis pariwisata di kota Bandung berbasis Web".

Menurut Melian dan Hilman, [1] menjelaskan tentang kurangnya pengelolaan serta publikasi ke masyarakat yang luas. Menurut Vicky Wulandari, Ahmad Suryan, Bambang Pudjoatmodjo tahun 2012 dijelaskan bahwa bagi orang yang belum pernah berkunjung ke Batam selalu kesulitan mencari petunjuk tempat pariwisata tersebut sehingga peneliti menambahkan artikel sebagai info pariwisata, serta daftar pengunjung untuk mengetahui seberapa banyak orang yang melihat website tersebut. [2], maka dari itu disimpulkan dengan mengelola data mengenai pariwisata akan dapat memudahkan para calon wisata untuk mencari informasi daerah wisata tersebut[4]. Dari jurnal inilah peneliti dapat membandingkan dan dapat mengembangkannya ke dalam sebuah sistem informasi yang lebih mudah, cepat, dan akurat dalam penyampaiannya. Peneliti membangun sistem informasi dengan menggunakan GOOGLE API sebagai petunjuk lokasi daerah yang menjadi tempat pariwisata budaya, meng-update informasi secara berkala supaya informasi tersebut tidak ketinggalan jaman dan memberikan keterangan secara jelas tentang letak lokasi serta informasi yang akan memuat fasilitas pelayanan informasi pariwisata dan budaya [3].

\section{METODOLOGI PENELITIAN}

Metode yang digunakan dalam pengujian menggunakan metode kuantitatif. Metode kuantitatif adalah metode pengumpulan data yang diperoleh berdasarkan perhitungan matematis yang berasal dari sample orang - orang atau penduduk yang diminta menjawab atas sejumlah pertanyaan tentang survey untuk menentukan frekuensi dan persentase tanggapan mereka. Dalam prosesnya, rumusan masalah dibentuk dalam kalimat Tanya yang pengumpulan datanya diperoleh dari survey menggunakan kuisioner sebagai instrumen. Penelitian ini menggunakan Research and Development (R\&D) yaitu proses untuk mengembangkan suatu produk baru untuk menyempurnakan produk yang telah ada [9]. Berikut beberapa tahapannya, yaitu : 
a) Research and information collecting

Dalam metode pengumpulan data, peneliti melakukan beberapa tahap agar data yang didapatkan akurat dan relevan.

1) Wawancara : wawancara dilaksanakan secara langsung terhadap Kepala Dinas Pariwisata dan Budaya Kabupaten Blora dengan cara tanya jawab berdasarkan tujuan penelitian.

2) Observasi : metode pengumpulan data melalui pengamatan langsung secara cermat di lapangan atau lokasi penelitian untuk memperoleh berbagai data konkret.

3) Studi pustaka : Data yang diperoleh dari perpustakaan atau buku referensi untuk mendapatkan informasi yang relevan dengan masalah yang sedang di teliti.

b) Planning

Setelah data - data yang didapatkan sudah terkumpul, perencanaan produk yang akan dibuat telah ditentukan sehingga dilakukan perencanaan dalam pembuatan desain website. Perencanaan pembuatan meliputi : Perancangan konsep dan desain, perancangan bentuk dan ukuran, serta perencanaan hasil akhir.

c) Develop preliminary form of product

Setelah melakukan perencanaan, maka dilanjutkan dengan pembuatan produk berupa website dengan menggunakan software diantaranya :

1) Macromedia Dreamweaver $\mathrm{Mx}$ digunakan untuk membuat bentuk objek yang akan digunakan sebagai tampilan menu - menu website. [7].

2) PHP digunakan sebagai bahasa pemrograman.

3) Google Api digunakan untuk membuat.

4) MySql digunakan sebagai databasenya [8].

d) Operational field testing

Uji validasi terhadap website Kantor Pariwisata dan Budaya Kabupaten Blora yang telah dihasilkan, dalam tahap uji validasi ini melibatkan pakar pendidikan komputer dan teknologi informasi serta Kepala Kantor Pariwisata dan budaya kabupaten Blora untuk mendapatkan evaluasi atas produk yang telah dihasilkan.

e) Final Product revision

Melakukan perbaikan-perbaikan terhadap website sesuai dengan evaluasi yang didaptkan setelah melakukan uji validasi sehingga menghasilkan produk akhir/final yang siap dipublikasikan.

f) Dissemination and implementation

Tahap terakhir yaitu mempublikasikan atau menyebarluaskan produk yang dikembangkan berupa website Kantor Pariwisata dan Budaya Kabupaten Blora yang akan menjadi media promosi dan informasi melalui internet.

Desain Penelitian pada gambar 1. memberikan gambaran tentang prosedur untuk mendapatkan informasi atau data yang diperlukan untuk menjawab pertanyaan penelitian. Oleh karena itu sebuah desain penelitian yang baik akan menghasilkan sebuah proses penelitian yang efektif dan efisien. Uji coba produk harus menggambarkan semua proses yang diperlukan dalam perencanaan dan pelaksanaan penelitian, yang membantu peneliti dalam pengumpulan dan menganalisis data. Secara singkat, uji coba produk dapat didefinisikan sebagai rencana dan struktur penyelidikan yang digunakan untuk memperoleh bukti - bukti dalam menjawab pertanyaan penelitian.

Metode yang digunakan dalam pengujian menggunakan metode kuantitatif. Metode kuantitatif adalah metode pengumpulan data yang diperoleh berdasarkan perhitungan matematis yang berasal dari sample orang - orang atau penduduk yang diminta menjawab atas sejumlah pertanyaan tentang survey untuk menentukan frekuensi dan persentase tanggapan mereka. Dalam prosesnya, rumusan masalah dibentuk dalam kalimat Tanya yang pengumpulan datanya diperoleh dari survey menggunakan kuisioner sebagai instrumen. 


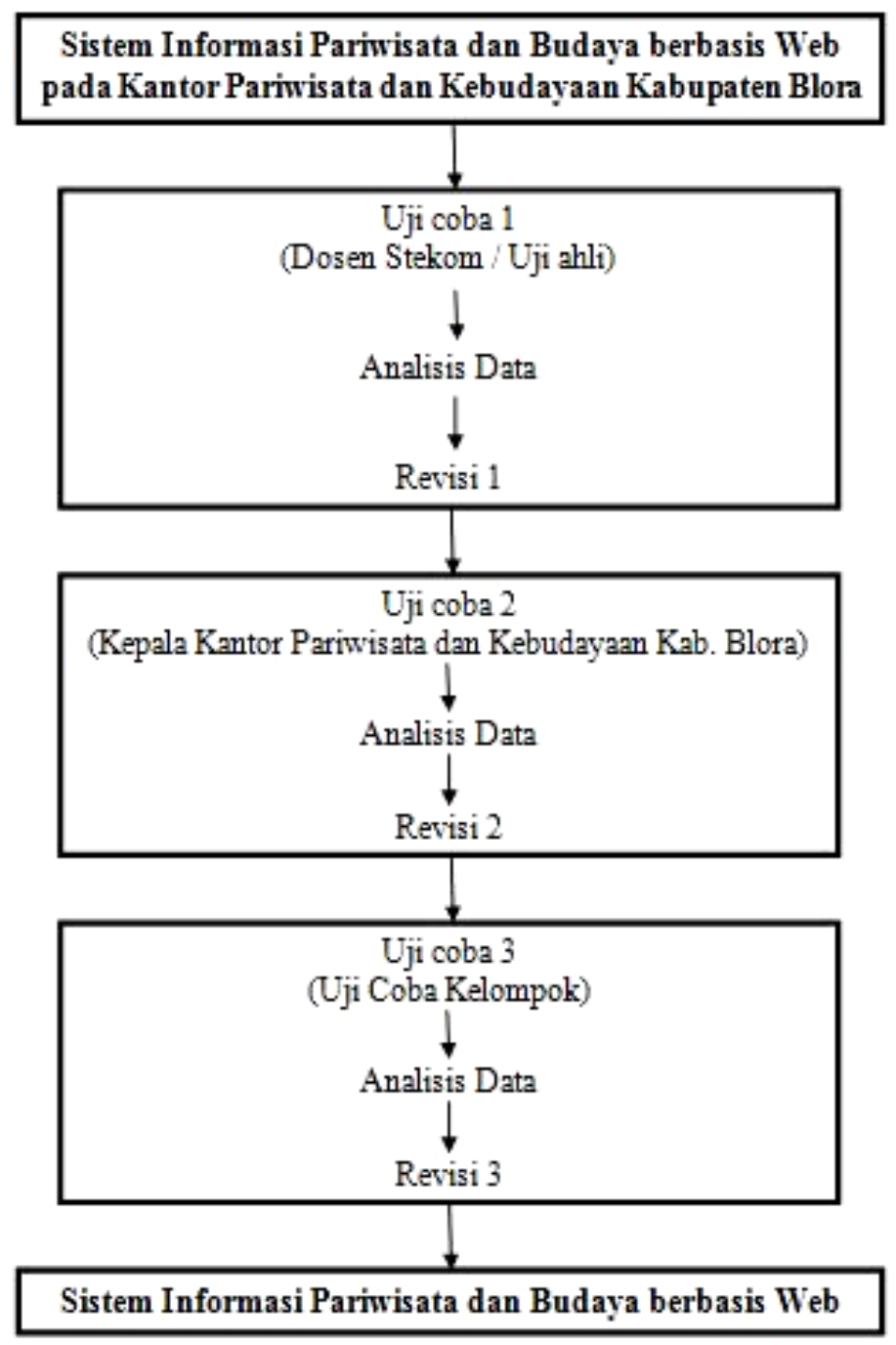

\section{Gambar 1. Desain Uji Coba}

\section{HASIL DAN PEMBAHASAN}

Hasil Penelitian diperoleh dari revisi - revisi data - data yang bersifat kuantitatif dari uji validasi yang telah dilakukan penulis. Uji validasi kelompok dilakukan dengan mengisi dan menyebarkan kuisioner dengan jumlah 10 pertanyaan kepada karyawan atau masyarakat atau mahasiswa PKL di Kantor Pariwisata dan Budaya Kabupaten Blora, sehingga didapatkan data-data hasil jawaban dari 30 responden yang dijabarkan sebagai berikut :

\begin{tabular}{|c|c|c|c|c|c|}
\hline & & nama & sangatbagus & bagus & biasasaja \\
\hline \multirow[t]{2}{*}{$\mathrm{N}$} & Valid & 32 & 30 & 30 & 30 \\
\hline & Missing & 0 & 2 & 2 & 2 \\
\hline \multicolumn{2}{|l|}{ Mean } & & 1.47 & 1.63 & 1.47 \\
\hline \multicolumn{2}{|c|}{ Std. Error of Mean } & & .190 & .176 & .171 \\
\hline \multicolumn{2}{|l|}{ Median } & & 2.00 & 2.00 & 1.50 \\
\hline \multicolumn{2}{|l|}{ Mode } & & 2 & 2 & 2 \\
\hline \multirow{2}{*}{\multicolumn{2}{|c|}{$\begin{array}{l}\text { Std. Deviation } \\
\text { variance }\end{array}$}} & & 1.042 & .964 & .937 \\
\hline \multirow{2}{*}{ Variance } & & & 1.085 & .930 & .878 \\
\hline & & & -101 & -.159 & -.032 \\
\hline \multicolumn{2}{|c|}{ Std. Error of Skewness } & & .427 & .427 & .427 \\
\hline \multicolumn{2}{|c|}{ Kurtosis } & & -1.130 & -.833 & -.773 \\
\hline \multirow{2}{*}{\multicolumn{2}{|c|}{$\begin{array}{l}\text { Std. Error of Kurtosis } \\
\text { Range }\end{array}$}} & & .833 & .833 & .833 \\
\hline & & & 3 & 3 & 3 \\
\hline \multicolumn{2}{|l|}{ Minimum } & & 0 & 0 & 0 \\
\hline \multicolumn{2}{|l|}{ Maximum } & & 3 & 3 & 3 \\
\hline \multirow{4}{*}{$\begin{array}{l}\text { Sum } \\
\text { Percentiles }\end{array}$} & & & 44 & 49 & 44 \\
\hline & 25 & & .75 & 1.00 & 1.00 \\
\hline & 50 & & 2.00 & 2.00 & 1.50 \\
\hline & 75 & & 2.00 & 2.00 & 2.00 \\
\hline
\end{tabular}

\begin{tabular}{|r|r|r|r|r|}
\hline \multicolumn{1}{|c|}{ jelek } & sangatjelek & cocok & sangatcocok & tdkcocok \\
\hline 30 & 30 & 30 & 30 & 30 \\
2 & 2 & 2 & 2 & 2 \\
1.27 & 1.53 & 1.30 & 1.33 & 1.27 \\
.214 & .202 & .174 & .168 & .185 \\
1.00 & 1.00 & 1.00 & 1.00 & 1.00 \\
0 & 1 & 1 & 1 & 1 \\
1.172 & 1.106 & .952 & .922 & 1.015 \\
1.375 & 1.223 & .907 & .851 & 1.030 \\
.264 & .074 & .364 & .387 & .266 \\
.427 & .427 & .427 & .427 & .427 \\
-1.440 & -1.316 & -.638 & -.510 & -.975 \\
.833 & .833 & .833 & .833 & .833 \\
3 & 3 & 3 & 3 & 3 \\
0 & 0 & 0 & 0 & 0 \\
3 & 3 & 3 & 3 & 3 \\
38 & 46 & 39 & 40 & 38 \\
.00 & 1.00 & 1.00 & 1.00 & .00 \\
1.00 & 1.00 & 1.00 & 1.00 & 1.00 \\
2.00 & 3.00 & 2.00 & 2.00 & 2.00 \\
\hline
\end{tabular}

Gambar 2. Tabel Frekuensi Rata Persentase 1 


\begin{tabular}{|c|c|c|c|c|}
\hline & Frequency & Percent & Valid Percent & $\begin{array}{c}\text { Cumulative } \\
\text { Percent }\end{array}$ \\
\hline Valid & 2 & 6.2 & 6.2 & 6.2 \\
\hline agung & 1 & 3.1 & 3.1 & 9.4 \\
\hline aini & 1 & 3.1 & 3.1 & 12.5 \\
\hline aji & 1 & 3.1 & 3.1 & 15.6 \\
\hline amora & 1 & 3.1 & 3.1 & 18.8 \\
\hline ana & 1 & 3.1 & 3.1 & 21.9 \\
\hline astuti & 1 & 3.1 & 3.1 & 25.0 \\
\hline bayu & 1 & 3.1 & 3.1 & 28.1 \\
\hline eko & 1 & 3.1 & 3.1 & 31.2 \\
\hline endah & 1 & 3.1 & 3.1 & 34.4 \\
\hline ismatul & 1 & 3.1 & 3.1 & 37.5 \\
\hline joko & 2 & 6.2 & 6.2 & 43.8 \\
\hline muhammad & 1 & 3.1 & 3.1 & 46.9 \\
\hline neng & 1 & 3.1 & 3.1 & 50.0 \\
\hline nur & 1 & 3.1 & 3.1 & 53.1 \\
\hline puji & 1 & 3.1 & 3.1 & 56.2 \\
\hline retno & 1 & 3.1 & 3.1 & 59.4 \\
\hline rosmiyati & 1 & 3.1 & 3.1 & 62.5 \\
\hline santi & 1 & 3.1 & 3.1 & 65.6 \\
\hline slamet & 1 & 3.1 & 3.1 & 68.8 \\
\hline suciawati & 1 & 3.1 & 3.1 & 71.9 \\
\hline sudarwo & 1 & 3.1 & 3.1 & 75.0 \\
\hline sugito & 1 & 3.1 & 3.1 & 78.1 \\
\hline sulistyo & 1 & 3.1 & 3.1 & 81.2 \\
\hline susana & 1 & 3.1 & 3.1 & 84.4 \\
\hline Tanggu & 1 & 3.1 & 3.1 & 87.5 \\
\hline vita & 1 & 3.1 & 3.1 & 90.6 \\
\hline wahyu & 1 & 3.1 & 3.1 & 93.8 \\
\hline wawan & 1 & 3.1 & 3.1 & 96.9 \\
\hline zaenal & 1 & 3.1 & 3.1 & 100.0 \\
\hline Total & 32 & 100.0 & 100.0 & \\
\hline
\end{tabular}

Gambar 3. Tabel Frequency Kuisioner

\begin{tabular}{|c|c|c|c|c|c|c|c|}
\hline \multicolumn{4}{|c|}{ Statistics } & \multirow[b]{3}{*}{$\begin{array}{c}\text { sangatsederh } \\
\text { anadanjelek }\end{array}$} & \multirow[b]{3}{*}{$\begin{array}{c}\text { terbacasanga } \\
\text { tjelas }\end{array}$} & \multirow[b]{3}{*}{ terbacajelas } & \multirow[b]{3}{*}{$\begin{array}{c}\text { terbacakuran } \\
\text { gjelas }\end{array}$} \\
\hline sangattdkcoc & sederhanada & sangatsederh & sederhanada & & & & \\
\hline $\begin{array}{ll}\text { ok } \\
\end{array}$ & $\begin{array}{r}\text { nbagus } \\
30\end{array}$ & $\frac{\text { anadanbagus }}{30}$ & $\begin{array}{l}\text { njelek } \\
30\end{array}$ & & & & \\
\hline 2 & 2 & 2 & 2 & 30 & 30 & 30 & 30 \\
\hline 1.40 & 1.47 & 1.23 & 1.23 & 2 & 2 & 2 & 2 \\
\hline .189 & .184 & .141 & .202 & 1.27 & 1.03 & 1.43 & 1.43 \\
\hline 1.00 & 1.00 & 1.00 & 1.00 & .185 & .155 & .190 & .177 \\
\hline $1=$ & 1 & 1 & 0 & 1.00 & 1.00 & 1.50 & 1.00 \\
\hline 1.037 & 1.008 & .774 & 1.104 & 1 & 1 & 2 & 1 \\
\hline 1.076 & 1.016 & .599 & 1.220 & 1.015 & .850 & 1.040 & .971 \\
\hline .087 & .206 & .515 & .325 & 1.030 & .723 & 1.082 & .944 \\
\hline .427 & 427 & 427 & .427 & .479 & .655 & -.007 & .201 \\
\hline-1.100 & -.977 & .354 & -1.219 & .427 & .427 & .427 & .427 \\
\hline 833 & 833 & $\begin{array}{l}.354 \\
833\end{array}$ & $\begin{array}{r}-1.219 \\
833\end{array}$ & -.751 & .185 & -1.126 & -.838 \\
\hline .833 & .833 & .833 & .833 & .833 & .833 & .833 & .833 \\
\hline 3 & 3 & 3 & 3 & 3 & 3 & 3 & 3 \\
\hline 0 & 0 & 0 & 0 & 0 & 0 & 0 & 0 \\
\hline 3 & 3 & 3 & 3 & 3 & 3 & 3 & 3 \\
\hline 42 & 44 & 37 & 37 & 38 & 31 & 43 & 43 \\
\hline .75 & 1.00 & 1.00 & .00 & .75 & .00 & .75 & 1.00 \\
\hline 1.00 & 1.00 & 1.00 & 1.00 & 1.00 & 1.00 & 1.50 & 1.00 \\
\hline 2.00 & 2.00 & 2.00 & 2.00 & 2.00 & 1.25 & 2.00 & 2.00 \\
\hline
\end{tabular}

Gambar 4. Tabel Frekuensi Rata Persentase 2 


\begin{tabular}{|r|r|r|r|}
\hline tdkterbaca & tdkmasalah & $\begin{array}{c}\text { cukupbermas } \\
\text { alah }\end{array}$ & $\begin{array}{c}\text { sangatberma } \\
\text { salah }\end{array}$ \\
\hline 30 & 30 & 30 & 30 \\
2 & 2 & 2 & 2 \\
1.50 & 1.30 & 1.43 & 1.27 \\
.190 & .174 & .177 & .172 \\
1.50 & 1.00 & 1.50 & 1.00 \\
12 & 1 & 2 & 1 \\
1.042 & .952 & .971 & .944 \\
1.086 & .907 & .944 & .892 \\
.000 & .364 & -.041 & .208 \\
427 & .427 & .427 & .427 \\
-1.113 & -.638 & -.914 & -.791 \\
.833 & .833 & .833 & .833 \\
3 & 3 & 3 & 3 \\
0 & 0 & 0 & 0 \\
3 & 3 & 3 & 3 \\
45 & 39 & 43 & 38 \\
1.00 & 1.00 & 1.00 & .75 \\
1.50 & 1.00 & 1.50 & 1.00 \\
2.00 & 2.00 & 2.00 & 2.00 \\
\hline
\end{tabular}

\begin{tabular}{|r|r|r|r|}
\hline sangatmudah & mudah & \multicolumn{1}{c|}{ sulit } & sangatsulit \\
\hline 30 & 30 & 30 & 30 \\
2 & 2 & 2 & 2 \\
1.40 & 1.47 & 1.13 & 1.50 \\
.189 & .184 & .190 & .178 \\
1.00 & 1.00 & 1.00 & 1.50 \\
12 & 1 & 0 & 17 \\
1.037 & 1.008 & 1.042 & .974 \\
1.076 & 1.016 & 1.085 & .948 \\
.087 & .206 & .305 & .000 \\
.427 & .427 & .427 & .427 \\
-1.100 & -.977 & -1.188 & -.890 \\
.833 & .833 & .833 & .833 \\
3 & 3 & 3 & 3 \\
0 & 0 & 0 & 0 \\
3 & 3 & 3 & 3 \\
42 & 44 & 34 & 45 \\
.75 & 1.00 & .00 & 1.00 \\
1.00 & 1.00 & 1.00 & 1.50 \\
2.00 & 2.00 & 2.00 & 2.00 \\
\hline
\end{tabular}

Gambar 5. Tabel Frekuensi Rata Persentase 3

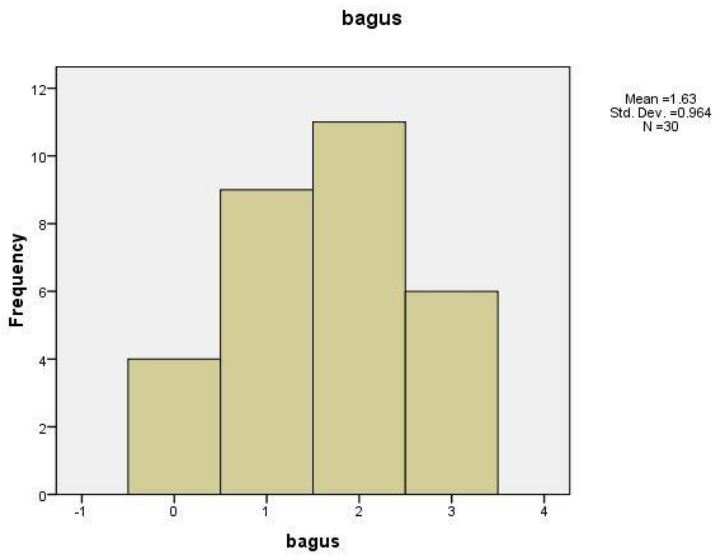

Gambar 6. Hasil Pengujian

Berdasarkan statistik tersebut di atas pada gambar 2, 3, 4, 5, dijelaskan bahwa dari data keseluruhan responden menyatakan web sistem informasi pariwisata dan budaya ini bagus dan siap d presentasikan. Hasil yang dicapai adalah standart deviasi sebesar 0,964 dan mean sebesar 1,63 nilai tertinggi dari frekuensi kuisioner adalah bagus (lihat gambar 6).

Pembuatan produk website Kantor Pariwisata dan Budaya menggunakan Macromedia dreamweaver $m x$, google API, MySQL. Proses pembuatan dibagi menjadi beberapa tahap yang dijabarkan sebagai berikut : 
a. Admin Wisata

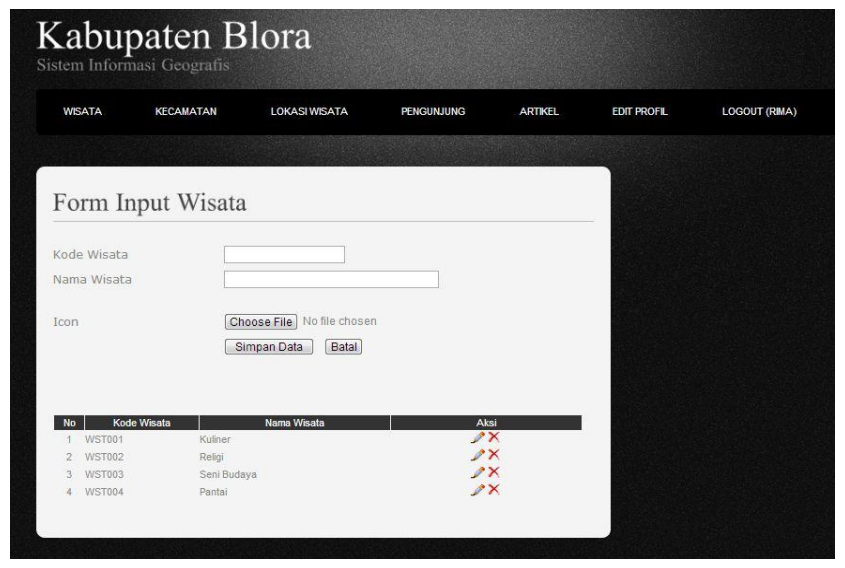

Gambar 7. Admin Wisata

b. Admin Lokasi Wisata

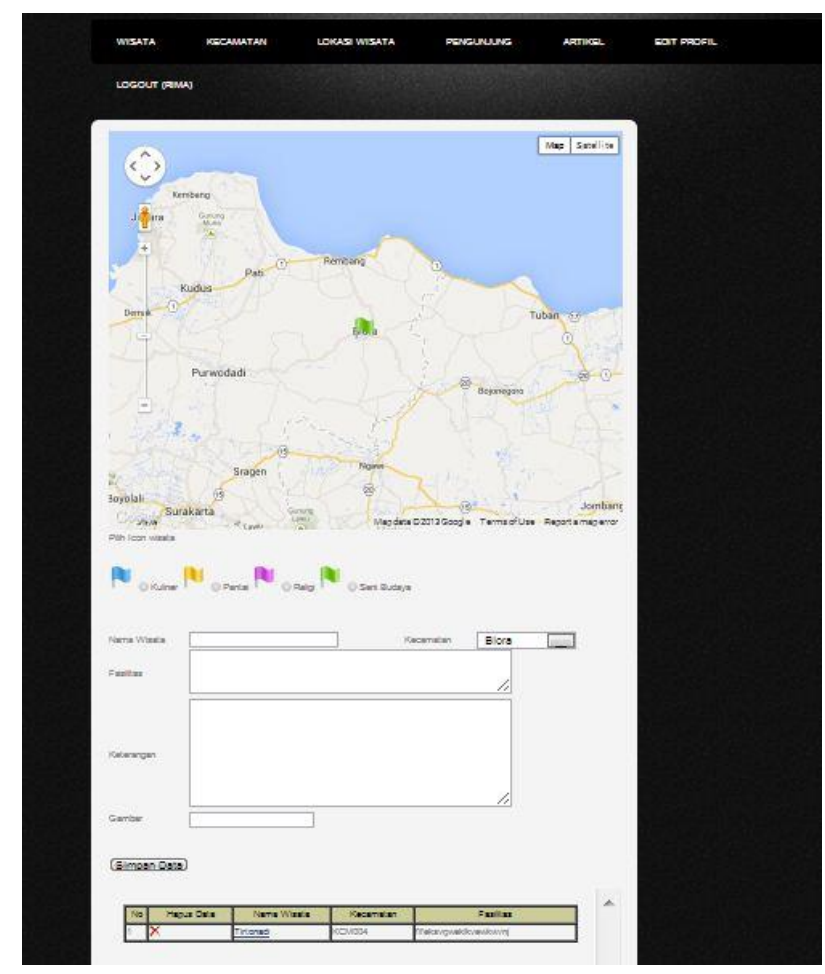

Gambar 8. Admin Lokasi Wisata

\section{KESIMPULAN} berikut:

Berdasarkan pembahasan dan evaluasi dari bab terdahulu, maka dapat ditarik kesimpulan sebagai

a. Sistem informasi pariwisata dan kebudayaan Blora berbasis Web ini dapat memberikan informasi yang lebih aktual kepada para pemakai (user) meliputi profil utama wisata, peta wisata blora, cinderamata, wisata budaya, dan makanan khas. Sehinggan mereka dapat mengetahui objek-objek wisata di daerah sekitar kita, khususnya masyarakat Blora dan masyarakat luar Blora pada umumnya.

b. Dengan menggunakan media website maka publikasi dari seluruh informasi pariwisata yang ada pada Dinas pariwisata dan kebudayaan Blora dapat dilakukan dengan efisien dan efektif, apabila terjadi perubahan-perubahan dapat lebih cepat diketahui oleh para pengunjung tanpa harus 
memakan waktu yang lama (pengunjung tidak terlambat untuk mengetahui perubahan perubahan tersebut).

c. Dengan pembuatan desain yang variatif dapat memberikan suatu tampilan yang menarik sehingga para pengunjung (User) mendapatkan kepuasan dalam melakukan penelusuran informasi tentang objek-objek di Blora.

\section{DAFTAR PUSTAKA}

[1] Melian, Hilman Agus, 2011. Jurnal "Perancangan dan Pembangunan Informasi Geografis Pariwisata di Kota Bandung"

[2] Wulandari, Ahmad Suryan, Bambang Pudjoatmodjo, 2012. Jurnal "Aplikasi Pengelolaan data untuk informasi pariwisata Kota Batam”.

[3] Mulyanto, Agus. 2009. Sistem Informasi Konsep dan Aplikasi. Yogyakarta: Pustaka Belajar

[4] Andri Kristanto, 2008. Perancangan Sistem Informasi dan Aplikasinya, Yogyakarta : Gaya Media.

[5] Gamal Suwantoro 2009, Dasar-dasar berpariwisata, Yogjakarta: Andi.

[6] Djoko Widagdo 2010, Kebudayaan Jawa. Jakarta : Balai Pustaka

[7] Kurniawan, Yahya, 2010. Microsoft Active Server Page, Jakarta: Elexmedia Komputindo

[8] Sutarman, 2012, "Membangun Aplikasi Web dengan PHP \& Mysql", Yogyakarta, Penerbit PT. Graha Ilmu

[9] Sugiyono. (2011). Metode Penelitian Kuantitatif Kualitatif dan R\&D. Bandung. Alfabeta 